\title{
Considering the role of incidental appendectomy during colonic interposition gastroesophageal reconstruction
}

\author{
Michelle Dugan, BS, ${ }^{a}$ Michael Sosin, MD, ${ }^{b}$ Raul Caso, MD, MSCI, ${ }^{c, d}$ Chaitanya Vadlamudi, MD, MBA, ${ }^{\text {, d }}$ \\ Mohammed Bayasi, MD, ${ }^{\mathrm{c}}$ and M. Blair Marshall, MD, ${ }^{\mathrm{d}}$ Washington, DC, and New York, NY
}

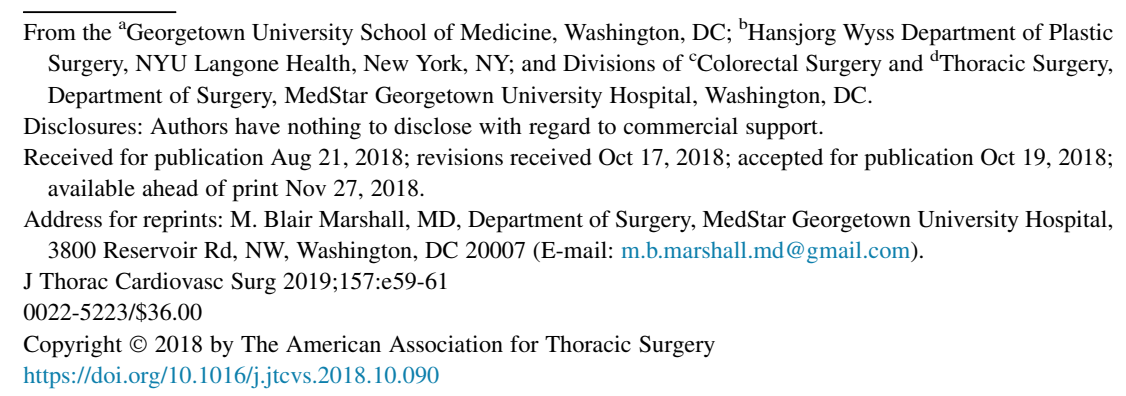

Colonic interposition following esophagectomy is associated with a complication rate as high as $50 \%{ }^{1}$ Anatomic rearrangement of the gastrointestinal tract makes postoperative management challenging in the setting of new onset abdominal pain, nausea, and vomiting. We present a case of perforated appendicitis 2 weeks following a completion esophagogastrectomy and left colonic interposition for gastroesophageal adenocarcinoma, representing, to our knowledge, the first case described in the literature. The purpose of this case report is to describe the clinical experience of perforated appendicitis following a colonic interposition and explore the potential implementation of an incidental appendectomy at the time of the initial procedure.

\section{CASE REPORT}

A 52-year-old man with T3 N0 gastric adenocarcinoma underwent neoadjuvant combination drug therapy with leucovorin, fluorouracil, and oxaliplatin followed by a minimally invasive Ivor Lewis esophagectomy and partial gastrectomy with gastric conduit reconstruction. Intraoperative margins were negative but final pathology revealed a positive distal margin requiring a completion gastrectomy with a left colon interposition and Roux-en-Y colojejunal reconstruction 6 weeks following his index procedure. The patient's postoperative course was complicated by a diaphragmatic hernia and a superficial surgical site infection treated nonoperatively. He was discharged on postoperative day 10 and 5 days later presented to an emergency department with a fever, fatigue, nausea, emesis, diffuse abdominal pain, and a leukocytosis of $20 \times 10^{3}$ cells $/ \mu \mathrm{L}$ with a neutrophilia. Computed tomography (CT) scan of the chest, abdomen, and pelvis (Figure 1) revealed perforated acute appendicitis with a periappendiceal abscess, not amenable to percutaneous drainage. The patient was treated with intravenous antibiotics, bowel rest, and total parenteral nutrition. An interval CT scan (Figure 2, A)

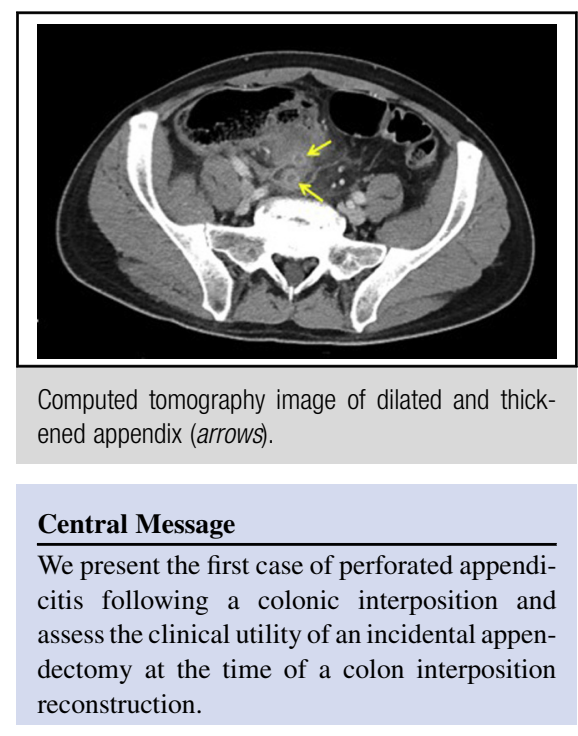

obtained on hospital day 10 (postoperative day 25) demonstrated absence of fluid collections and interval improvement of inflammation. The patient remained on a 3-week antibiotic course and was followed in the outpatient setting. He was tolerating oral intake 7 weeks postdischarge with a CT scan at 12 weeks (Figure 2, B) demonstrating resolution of the appendiceal inflammation.

\section{DISCUSSION}

The morbidity of a colonic interposition makes ongoing follow-up challenging in the presence of new onset

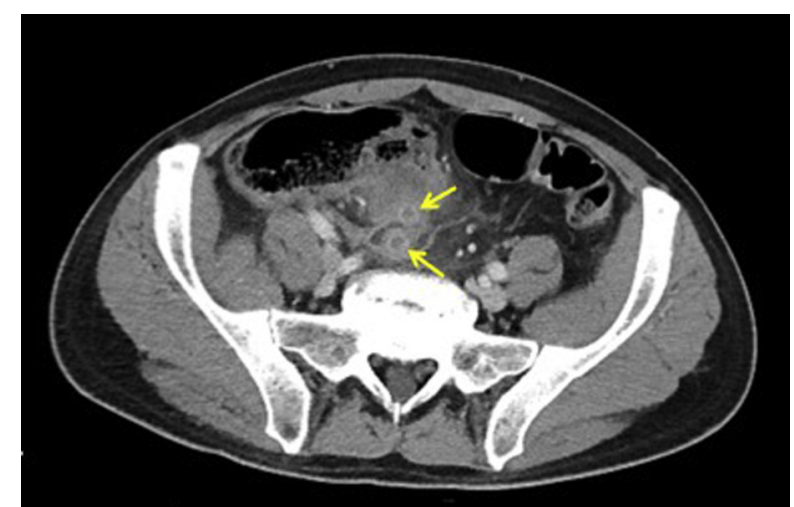

FIGURE 1. Computed tomography image of dilated and appendiceal wall thickening (arrows), showing periappendiceal inflammatory changes with an adjacent crescentic fluid collection adjacent to the appendiceal base. 

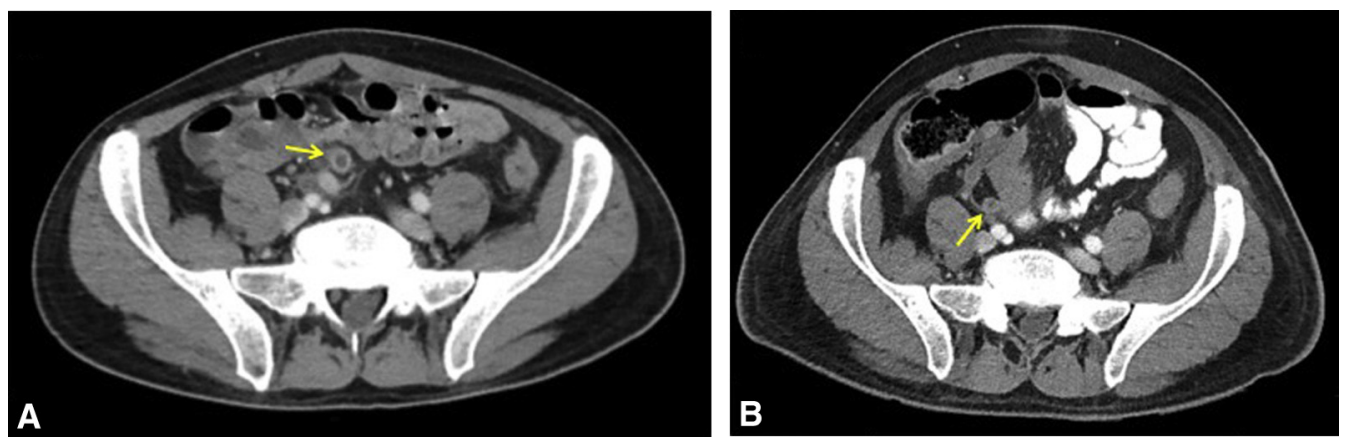

FIGURE 2. A, Interval computed tomography scan 10 days following acute appendicitis (postoperative day 25) demonstrating improvement in appendiceal inflammation (arrow) without a need for percutaneous drainage. B, Resolution of appendiceal inflammation (arrow) and retroperitoneal inflammation 12 weeks following nonoperative management of acute appendicitis.

abdominal pain. This can be the result of chronic incisionrelated pain, rearrangement of appendiceal location (if the right colon was used), or ongoing inflammation. This is the first case report of perforated appendicitis following a colonic interposition. There were 2 indications for nonoperative treatment: presence of perforation and unfavorable timing in development of disease (3 weeks postoperative) making the patient's abdomen a hostile environment for reoperation. This prompted our group to consider an incidental appendectomy during a colonic interposition, as has been described in the management of other disease pathologies, ${ }^{2}$ and perform an epidemiologic exercise to determine its potential benefit.

The incidence of acute appendicitis in North America is 100 out of 100,000 annually, affecting an estimated 378,614 patients in $2015 .{ }^{3}$ Approximately $30 \%$ of patients admitted to hospital with acute appendicitis will experience perforation, resulting in longer hospital stays and higher rates of complications attributing to higher costs compared with unperforated appendicitis. ${ }^{4}$ Incidental appendectomy is less common today, although it is routinely performed as part of the Ladd's procedure for treatment of midgut volvulus and intestinal malrotation and selectively during intestinal resection for Crohn's disease. ${ }^{2}$ Acute appendicitis during the early postoperative period continues to complicate abdominopelvic procedures, posing a challenge to surgeons, recovering patients, and health care systems. ${ }^{5}$ Significant cost savings potentially associated with incidental appendectomy has been described through a hypothetical Markov decision model. ${ }^{6}$

To avoid misdiagnosis, delay in diagnosis, and minimize radiation exposure, incidental appendectomy during colonic interposition warrants consideration. In the case of colonic interposition, the consequences of perforated appendicitis, including sepsis, malnutrition, and pain, likely outweigh the risk of an appendectomy-related complication. An appendectomy should not add significant time or risk of infection because colon interposition is already a
Centers for Disease Control and Prevention class 2, cleancontaminated procedure.

An epidemiologic approach to this problem is challenged by the infrequent nature of this procedure. Data were selected based on geographic availability. Calculation of a hypothetical number needed to treat based on an incidence of appendicitis following colonic interposition, given that this is the first reported case, confers a conservative estimate of benefit. Absolute risk reduction was calculated using the annual rate of appendicitis in North America $\left(100\right.$ per $\left.100,000^{3}\right)$ and the rate of appendicitis in colonic interposition patients (1 per 23.43) using the average annual colonic interpositions performed in England, ${ }^{7}$ likely to be an underestimation of the incidence in the United States. This hypothetical model yielded an absolute risk reduction of 0.0417 , with a hypothetical number needed to treat of 24 patients. Contradictory to this observation, Brown and colleagues ${ }^{8}$ described more than 1800 colon interpositions in their meta-analysis but appendicitis was not described as a complication. However, they failed to report duration of follow-up and did not capture patient comorbidities such as prior appendectomy. Nevertheless, the benefit of incidental appendectomy during colon interposition appears to be anecdotal and thus it warrants further investigation because it remains unclear whether there is any theoretical or actual benefit. With increased reporting, future evidence may elucidate its purported benefits.

\section{References}

1. Bakshi A, Sugarbaker DJ, Burt BM. Alternative conduits for esophageal replacement. Ann Cardiothorac Surg. 2017;6:137-43.

2. Healy JM, Olgun LF, Hittelman AB, Ozgediz D, Caty MG. Pediatric incidental appendectomy: a systematic review. Pediatr Surg Int. 2016;32:321-35.

3. Ferris M, Quan S, Kaplan B, Molodecky N, Ball CG, Chernoff GW, et al. The global incidence of appendicitis. Ann Surg. 2017;266:237-41.

4. Barrett ML, Hines AL, Andrews RM. Trends in rates of perforated appendix, 2001-2010: statistical brief \#159. Rockville, MD: Agency for Healthcare Research and Quality; 2013. Available at: http://www.hcup-us.ahrq.gov/reports/statbriefs/ sb159.pdf. Accessed April 1, 2018. 
5. Charak GS, Florin WD, Zitsman JL. Acute appendicitis following laparoscopic sleeve gastrectomy in an adolescent. J Pediatr Surg Case Rep. 2015; 3:82-3.

6. Newhall K, Albright B, Tosteson A, Ozanne E, Trus T, Goodney PP. Costeffectiveness of prophylactic appendectomy: a Markov model. Surg Endosc. 2017:31:3596.
7. Fisher RA, Griffiths EA, Envison F, Mason RC, Zylstra J, Davies AR, et al. A national audit of colonic interposition for esophageal replacement. Dis Esophagus. 2017;30:1-10.

8. Brown J, Lewis WG, Foliaki A, Clark GWB, Blackshaw GRJC, Chan DSY, et al Colonic interposition after adult oesophagectomy: systematic review and metaanalysis of conduit choice and outcome. J Gastrointest Surg. 2018;22:1104-11. 